\title{
INTRACORONARY ADENOVIRUS-MEDIATED TRANSFER OF IMMUNOSUPPRESSIVE CYTOKINE GENES PROLONGS ALLOGRAFT SURVIVAL
}

Ron Brauner, MD

Masaki Nonoyama, MD

Hillel Laks, MD

Davis C. Drinkwater, Jr., MD

Sharon McCaffery, MS

Thomas Drake, MD

Arnold J. Berk, MD

Luyi Sen, MD

Lily Wu, MD, PhD
Background: Intracoronary transfer and expression of recombinant genes in the intact heart is now feasible. In the transplant setting, local modulation of host immune responses by a genetically modified allograft may offer an attractive alternative to systemic immunosuppression. Methods: We tested the efficacy and in vivo effect of intracoronary transfer of two immunosuppressive cytokine genes. First-generation E1-deleted adenoviral vectors expressing the Epstein-Barr virus interleukin-10 (AdSvIL10) or human transforming growth factor- $\beta_{1}$ (AdCMVTGF- $\beta$ ) were used. Rabbit cardiac allografts were transduced during cold preservation by slow $(1 \mathrm{ml} / \mathrm{min})$ intracoronary infusion of $10^{10} \mathrm{pfu} / \mathrm{gm}$ diluted viral vectors and then implanted heterotopically. Controls included E1-deleted adenovirus (Ad5dl434) and AdCMVLacZ. Beating allografts were collected on day 4 for analysis of gene transfer efficacy and distribution. Additional grafts were used for evaluation of alloreactivity $(n=34)$. Results: Mean allograft viral uptake was $81 \%$ (up to $91 \%$ ). Polymerase chain reactions and reverse transcription-polymerase chain reactions confirmed the presence and expression of both genes in the grafts. $\beta$-Galactosidase staining in AdCMVLacZ-infected grafts demonstrated efficient gene expression, which was highest $(100 \%)$ in subepicardial regions. More homogeneous transmyocardial distribution of the transgene (in $25 \%$ to $40 \%$ of cells) could be achieved by pulsatile slow delivery. Allograft survival was $6.9 \pm 0.9$ days in controls $(n=12), 11.1 \pm 1.7$ days in AdCMVTGF- $\beta$-infected grafts $(n=$ $\left.11, p<10^{-4}\right)$, and 11.2 \pm 3 days in AdSvIL10-infected grafts $(n=11, p<$ $\left.10^{-4}\right)$. Histologic scores (blinded) showed significantly $(p<0.005)$ higher regression coefficients for rejection in controls compared with both cytokine-transduced groups. Perioperative administration of cyclosporine $A$ (INN: ciclosporin) to recipients had no effect on survival of AdCMVTGF$\beta$-infected grafts but reduced survival of AdSvIL10-infected grafts. Conclusions: Intracoronary gene transfer of immunosuppressive cytokines to cardiac allografts is efficient and effectively prolongs graft survival. Vectors that would induce long-term expression of such genes may make this approach clinically applicable. (J Thorac Cardiovasc Surg 1997;114:923-33)
From the Division of Cardiothoracic Surgery, University of California at Los Angeles Medical Center, Los Angeles, Calif.

Received for publication March 11, 1997; revisions requested April 22, 1997; revisions received May 7, 1997; accepted for publication May 7, 1997.

Address for reprints: Hillel Laks, MD, Division of Cardiothoracic Surgery, UCLA Medical Center, 62-182A Center for the Health Sciences, 10833 Le Conte Ave., Los Angeles, CA 90095 .

Copyright (c) 1997 by Mosby-Year Book, Inc.

0022-5223/97 $\$ 5.00+0 \quad \mathbf{1 2 / 1 / 8 3 2 3 7}$
$1 /$ ith the recently developed science of gene therapy, a new era in cardiovascular therapeutics has been opened. Localized expression of recombinant genes in the transplanted heart may contribute to the prevention and treatment of major problems in transplantation, such as allograft accelerated coronary atherosclerosis and acute rejection. An immediate application of allograft-targeted gene therapy is local modulation of the host immune response by a genetically altered allograft. Soluble proteins secreted within the transplanted organ may act locally and specifically while avoiding systemic 
Table I. Cytokine levels in protein extract and serum from allografts infected with $T G F-\beta_{\perp}$ and $v I L-10$-encoding first-generation adenoviral vectors

\begin{tabular}{cllll}
\hline & & & \multicolumn{2}{c}{ Transgene expression } \\
\cline { 4 - 4 } Vector & Dose & $n$ & \multicolumn{1}{c}{ In tissue } & In senum \\
\hline AdCMVTGF- $\beta$ & $>10^{10} \mathrm{pfu} / \mathrm{gm}$ & 5 & $4 \mathrm{ng} / \mathrm{gm}(2.2$ to 7$)$ & Up to $1 \mathrm{ng} / \mathrm{ml}$ \\
AdCMVTGF- $\beta$ & $<10^{10} \mathrm{pfu} / \mathrm{gm}$ & 5 & $1.9 \mathrm{ng} / \mathrm{gm}(1.6$ to 3.6$)$ & Not detected \\
AdSVIL10 & $>10^{10} \mathrm{pfu} / \mathrm{gm}$ & 4 & $0.3 \mathrm{ng} / \mathrm{gm}(0.05$ to 0.9$)$ & Up to $0.5 \mathrm{ng} / \mathrm{ml}$ \\
AdSvIL10 & $<10^{10} \mathrm{pfu} / \mathrm{gm}$ & 6 & Not detected & Not detected \\
\hline
\end{tabular}

A double-antibody enzyme-linked immunosorbent assay was used to detect cytokine expression in allograft protein extract on postoperative day 4 . Levels shown are averaged values for left and right ventricles and intraventricular septum and are expressed as nanograms per gram of donor heart. TGF- $\beta_{1}$ expression correlated with the infused quantity of viral vectors and was not detected in significant amount in control Ad5dl434-infected grafts. vIL-10 expression in tissue was undetectable when vector dose was lower than $10^{10} \mathrm{pfu} / \mathrm{gm}$ of donor heart and minor even at higher doses. However, both cytokines were detected in the recipient serum.

side effects and the need for conventional systemic immunosuppression.

Gene transfer into the adult heart has been achieved in vivo by direct myocardial injection ${ }^{1-5}$ and more recently by intracoronary infusion. ${ }^{6-10}$ The latter method is preferable when considering clinical application, because direct injection results in uneven distribution of transgene expression and local inflammation. ${ }^{4,5}$ By way of increasing the efficacy of gene transfer and facilitating recombinant DNA uptake by target cells, vehicles for gene transfer such as cationic liposomes, viral vectors, or a combination of both ${ }^{10}$ have been successfully used. Given the specific attributes of nondividing cardiac cells, recombinant adenoviral vectors emerged as the most effective vehicle for transport of genes into the heart under both normothermic ${ }^{7,9}$ and hypothermic ${ }^{6}$ conditions. To date, studies of gene transfer in the heart have been largely limited to the use of reporter genes to demonstrate transgene expression and the efficacy of various transfer strategies.

To evaluate the applicability of intracoronary gene therapy for cardiac transplantation in vivo, we constructed first-generation recombinant adenoviral vectors encoding two immunosuppressive cytokines, viral interleukin-10 (vIL-10) and human transforming growth factor- $\beta_{1}$ (TGF- $\left.\beta_{1}\right)$. In addition to welldocumented immunosuppressive properties in vitro, both have recently been shown to inhibit host responses in models of alloreactivity in vivo. IL-10, an $18 \mathrm{kd}$ polypeptide initially described as cytokine synthesis inhibitory factor, is best known for its downregulating action on the effector functions of Th1 helper clones, potently inhibiting production of IL-2, TNF- $\alpha$, TNF- $\beta$, and interferon- $\gamma$. The activation of monocyte-macrophages is thus effectively suppressed, as is the release of monokines and their ability to serve as accessory cells for antigen presen- tation and stimulation of Th and natural killer cells. ${ }^{11-13}$ The viral homologue (IL-10 homologue) used in this study is encoded by an open-reading frame (BCRF1) in the Epstein-Barr virus genome. ${ }^{14}$ This protein shares most of the biologic activities of the cellular cytokine. Although it has lower in vitro potency ${ }^{11}$ it seems more suitable for targeted immunosuppression in alloreactivity models, because of lower mast cell and thymocyte co-stimulatory action. TGF- $\beta_{1}$ is an omnipresent cytokine, with potent down-regulating functions in both cellular and humoral alloreactive pathways. It suppresses clonal generation and production of IL-2, IL-6, and TNF by alloantigen-specific $\mathrm{T}$ lymphocytes at femtomolar levels ${ }^{15,16}$ and effectively reduces killer activity and pore-forming protein gene expression in CD8 + lymphokine-activated killer cells. ${ }^{17}$ In addition, B-cell proliferation and immunoglobulin production are greatly reduced.

We have previously tested the ability of the new E1-deleted adenoviral vectors to express the encoded cytokine genes in cardiac allografts, and have developed a model for efficient ex vivo intracoronary transfer of the cytokine genes during cold preservation. ${ }^{18}$ The efficacy of various methods of vector delivery, as well as the dose-dependence of transgene expression, were evaluated. Continuous slow intracoronary infusion of diluted vectors was found superior to bolus high-pressure injection, resulting in absorption of up to $91 \%$ of infused vectors (mean $80 \%$ ). This uptake rate was sustained with administered vector doses as high as $6 \times 10^{10} \mathrm{pfu} / \mathrm{gm}$ of donor heart. An exposure time of at least 20 minutes was required to obtain detectable transgene expression in the allografts and recipient serum on postoperative day 4 . This method of delivery resulted in measured tissue protein levels, as shown in Table I.

In the present study we used the slow intracoro- 
nary vector delivery method and examined the resulting transmyocardial distribution and magnitude of expression of a reporter gene, the Escherichia coli (E. coli) $\beta$-galactosidase. Transcription of the cytokine genes was documented by reverse transcription-polymerase chain reaction (RT-PCR). We then sought to determine whether immunosuppressive cytokine genes similarly administered can prolong allograft survival in vivo.

\section{Methods}

Viral vectors. A recombinant adenovirus expressing vIL-10 (AdSvIL10) was constructed as follows: A 520 bp EcoRI fragment containing the Epstein-Barr virus BCRF1 open reading frame (vIL-10) derived from $\operatorname{pcDSR} \alpha-B C R F 1^{14}$ (kindly provided by Dr. Kevin Moore, DNAX, Palo Alto, Calif.) was first cloned into a modified pBS SK+ (Stratagene Inc., La Jolla, Calif.), with its KpnI site changed to a BgllI site, resulting in pBS-BCRFl. Then the BglII to BamHI BCRFl containing fragment from pBS-BCRFl was inserted between the SV40 early promoter and the SV40 polyA site of pAdDB. pAdDB is derived from a pUC-based plasmid pAd2.17 $7^{19}$ containing Ad2 left end sequences from nucleotide 1 to 6228 (HindIII site) with its E1 region from nucleotide 341 to 3321 replaced by an expression cassette containing an SV40 early promoter, splice site, and polyA site from pXPRS + (Clontech Inc., Palo Alto, Calif.). In the resultant plasmid pAdSvIL10, the direction of VIL-10 gene transcription is leftward relative to the standard $\mathrm{Ad} 2$ map. AdSvIL10 recombinant virus was constructed by co-transfection of 293 cells (that constitutively express E1 proteins) with pAdSVvIL10 and dl309 viral $\mathrm{DNA}^{20}$ cut with $\mathrm{XbaI}$ and ClaI. Clones of recombinant virus were identified by restriction digestion and Southern blot analysis of Hirt DNA from infected 293 cells.

The AdCMVTGF- $\beta_{1}$ was constructed as follows: the $1.3 \mathrm{~kb}$ hTGF- $\beta_{1}$ complementary DNA (cDNA) fragment, flanked by $E c o$ RI sites, was cloned into the EcoRI site of pHCMVspllacZ, ${ }^{21}$ replacing the LacZ gene. The resultant plasmid pHCMVhTGF- $\beta$ has the human TGF- $\beta$ gene downstream from the CMV IE promoter and contains the SV40 splice signal and polyA site. Co-transfection into 293 cells with pHCMVhTGF- $\beta$ and truncated dl309 viral DNA resulted in generation of AdCMVTGF- $\beta_{1}$.

The control "empty" virus Ad5d1434 has deletions of the entire E1A and most of the E1B region. ${ }^{22}$ The AdCMVLacZ virus, which encodes the $E$. coli LacZ gene with an $\mathrm{N}$-terminal nuclear localization signal, was constructed by co-transfection of pACCMVßgal (kindly provided by Robert D. Gerard) and pJMI7. ${ }^{23}$

All recombinant viruses were plaque purified on 293 cells three successive times and grown into a high titer stock of greater than $10^{10} \mathrm{pfu} / \mathrm{ml}$ as assayed by plaque formation on 293 cells. The ability of cytokine-encoding vectors to express the transgenes was confirmed by enzyme-linked immunosorbent assay detection of both vIL-10 and TGF- $\beta_{1} 24$ hours after infection in 293 cell culture supernatant.
Experimental procedures. The rabbit heterotopic model of cardiac transplantation was previously described ${ }^{18}$ In brief, New Zealand White donors (1.7 to 2 $\mathrm{kg}$, Charles River Laboratories, St. Constant, Quebec, Canada) and recipients (5 to $5.5 \mathrm{~kg}$, Irish Farms, Norco, Calif.) were purchased from genetically and geographically unrelated vendors. All animals received humane care in compliance with the "Principles of Laboratory Animal Care" formulated by the National Society for Medical Research and the "Guide for the Care and Use of Laboratory Animals" prepared by the Institute of Laboratory Animal Resources and published by the National Institutes of Health (NIH Publication No. 86-23; revised 1985). General anesthesia was induced intravenously with ketamine $(10 \mathrm{mg} / \mathrm{kg})$ and acepromazine $(1 \mathrm{mg} / \mathrm{kg})$ and maintained with inhaled $1.5 \%$ isoflurane in oxygen by means of mechanical ventilation. Heparin $(200 \mathrm{mg} / \mathrm{kg}$ ) was given intravenously to both donors and recipients. Recipients received cefazolin $(40 \mathrm{mg} / \mathrm{kg})$ before incision. After sternotomy, the donor heart was arrested with University of Wisconsin solution $(15 \mathrm{ml})$, then excised and preserved in University of Wisconsin solution at $4^{\circ} \mathrm{C}$. After intracoronary gene transfer (see below), donor hearts were transplanted in recipients in the heterotopic cervical position, by anastomosing the donor aorta and pulmonary artery to the recipient right carotid artery and jugular vein, respectively. Topical cooling of donor hearts was maintained throughout the procedure. Ischemic time was 50 to 60 minutes. All allografts resumed spontaneous vigorous contraction within minutes of reperfusion. Cessation of mechanical activity before day 4 occurred in $10 \%$ and was considered to be due to technical failure.

Intracoronary gene transfer. During preservation at $4^{\circ} \mathrm{C}$, the donor aorta was cannulated. Viral vectors were resuspended in $20 \mathrm{ml}$ cold University of Wisconsin cardioplegic solution and administered by slow intracoronary infusion at $1 \mathrm{ml} / \mathrm{min}$. The total vector dose of $10^{10} \mathrm{pfu} / \mathrm{gm}$ of donor heart (mean weight 5 to $5.5 \mathrm{gm}$ ) was infused over 20 minutes. This constitutes an estimated multiplicity of infection of 20 viral particles per cell. After administration of at least $10 \mathrm{ml}$, coronary sinus effluent was collected for determination of viral titers.

Specimen processing. Allografts were inspected twice daily by direct palpation and given a score for mechanical activity, size, and consistency. For evaluation of cytokine transcripts and reporter gene expression, specimens were collected on postoperative day 4. For evaluation of allogenicity, other grafts were collected when mechanical activity became imperceptible. Transmural specimens from the left and right ventricular free walls and intraventricular septum were collected for each allograft.

$P C R$. Flanking primers were designed for internal regions of both transgenes: for vIL-10-a 461 bp region (sense: 5'-ATGGAGCGAAGGTTAGTGGTC A-3', antisense: 5'-CCTGGCTTTAATTGTCATGTATGCT$3^{\prime}$ ); for TGF- $\beta_{1}-$ a 243 bp region (sense: 5'-GCCCTGGACACCAACTATTGC-3', antisense: 5'-TTGCGGCCCACGTAGTACA-3'). DNA was extracted from specimens snap-frozen after cessation of mechanical activity, by the proteinase $\mathrm{K}$ incubation method: samples were crushed to fine powder and suspended in digestion buffer $(100 \mathrm{mmol} / \mathrm{L} \mathrm{NaCl}, 10 \mathrm{mmol} / \mathrm{L}$ tromethamine-Cl, 
$25 \mathrm{mmol} / \mathrm{L}$ ethylenediaminetetraacetic acid, $0.5 \%$ sodium dodecylsulfate, $\mathrm{pH} 8.0,0.1 \mathrm{mg} / \mathrm{ml}$ proteinase $\mathrm{K}$ ) at 80 $\mathrm{mg} / \mathrm{ml}$ for 1 hour. Phenol/chloroform/isoamyl alcohol $(25: 24: 1)$ was added in equal volume, and then the upper aqueous phase was separated by centrifugation. This step was repeated with and without chloroform; then two volumes of $100 \%$ ethanol and $10 \%$ sodium acetate $(\mathrm{pH}$ 5.2) were added at $-20^{\circ} \mathrm{C}$ for 1 hour. DNA precipitate was dried and resuspended in water at room temperature. PCR was performed in a DNA thermal cycler (PerkinElmer, Norwalk, Conn.) and consisted of 30 cycles (denaturing: $94^{\circ} \mathrm{C}-1^{\prime}$; annealing of primers: $55^{\circ} \mathrm{C}-1^{\prime}$; and extension: $\left.72^{\circ} \mathrm{C}-1^{\prime}\right)$. PCR products were separated by electrophoresis in $1.2 \%$ agarose gel and then stained with ethidium bromide. Expression plasmids used for vector construction served as positive controls.

$R T-P C R$. Total RNA was isolated from frozen specimens collected 4 days after the operation, by means of the lithium chloride/urea method. ${ }^{24}$ cDNA was obtained by random primer reverse transcription of RNA using 200 units of SuperScript II Reverse Transcriptase (GibcoBRL RT-PCR kit, Gaithersburg, Md.). The RNA/primer mixture was incubated at $42^{\circ} \mathrm{C}$ for 60 minutes, then $70^{\circ} \mathrm{C}$ for 15 minutes. cDNA was amplified with 1 unit of Taq DNA polymerase (Gibco-BRL) and $0.2 \mu \mathrm{M}$ of each primer to a final volume of $100 \mu \mathrm{l}$, using the two specific primers described above for vIL-10 and human TGF- $\beta_{1}$. Thirty-five cycles of amplification were carried out in a thermocycler (GeneAmp PCR System 9600, PerkinElmer) and consisted of denaturing at $94^{\circ} \mathrm{C}$ for 30 minutes, primer annealing at $55^{\circ} \mathrm{C}$ for 45 minutes, and primer extension at $72^{\circ} \mathrm{C}$ for 30 minutes. Before cycling, the reaction mixtures were preheated at $94^{\circ} \mathrm{C}$ for 2 minutes and after amplification an extra 10 minutes were added for extension at $72^{\circ} \mathrm{C}$. RT-PCR products were run on $1.2 \%$ agarose gel, transferred to nylon membranes, and probed for the presence of vIL-10 and TGF- $\beta_{1}$ using a random primer $\left({ }^{32} \mathrm{P}\right) \mathrm{dATP}-\mathrm{labeled}$ probe.

$\beta$-Galactosidase expression. Normally contracting grafts were collected on postoperative day 4 , and specimens were embedded in ornithine carbamoyltransferase (O.C.T.), then rapidly frozen in liquid nitrogen. Sections $10 \mu \mathrm{m}$ thick were fixed in $0.2 \%$ glutaraldehyde and $2 \%$ formaldehyde in phosphate-buffered saline (PBS) solution for 5 minutes at $4^{\circ} \mathrm{C}$. After being washed three times with phosphate-buffered saline solution at room temperature, the sections were stained for $\beta$-galactosidase by overnight incubation with $\mathrm{X}$-gal (5-bromo-4-chloro-indolyl $\beta$-D-galactopyranoside) at $37^{\circ} \mathrm{C}$. Cells expressing $\beta$-galactosidase showed intense blue staining. To quantify expression, positive as well as total cells were counted per high-power field $(\times 400)$. At least 10 fields per specimen from different subepicardial and subendocardial areas were examined.

Histologic examination. After graft failure, transmural specimens from the left and right ventricular free walls and intraventricular septum were fixed in $10 \%$ formalin. Slices $10 \mu \mathrm{m}$ thick were stained with hematoxylin and eosin. Rejection scores were assigned by a pathologist unaware of study design, based on the standard grading nomenclature established by the International Society for Heart Transplantation. ${ }^{25}$
Data analysis. Data are expressed as mean \pm standard deviation. Allograft survival curves produced with the Kaplan-Meier product limit method were compared with the Mantel-Cox log rank test. Rejection slope coefficients were compared with the use of one-way analysis of variance and significant differences were further tested by means of the Bonferroni $t$ test for multiple comparisons. Significance level was set at $p<0.05$.

\section{Results}

Vector absorption, detection, and expression. Using intracoronary delivery at a rate of $1 \mathrm{ml} / \mathrm{min}$ and vector quantity of $10^{10} \mathrm{pfu} / \mathrm{gm}$ of donor heart, average uptake of vectors by the grafts (defined as coronary sinus output titer $\times 100$ /delivered titer) was $81 \% \pm 5.6 \%$. All four vectors were absorbed equally. Inserted cytokine DNA sequences were detected by amplification (PCR) in all grafts infected with the AdSvIL10 and AdCMVTGF- $\beta$ (Fig. $1, a)$, but not in controls. This finding is consistent with the presence of both transferred genes in graft tissue after cessation of mechanical activity. RTPCR (Fig. 1, $b$ ) demonstrated the presence of both cytokine transcripts in the grafts, confirming successful gene transfer and expression in myocardial cells on postoperative day 4 .

Distribution and magnitude of transgene expression. The slow intracoronary flow of vectors brought about uneven distribution of expression of the $\beta$-galactosidase reporter gene (Fig. 2, $A$ ). Subepicardial perivascular regions expressed $\beta$-galactosidase in up to $100 \%$ of cells (Fig. 2, B); however, the amount of stained cells in mid-wall and subendocardial regions was only $5 \%$ to $20 \%$ (mean $12 \%$, Fig. 2, C). In view of this, we attempted to achieve more homogeneous transgene expression throughout the myocardium by increasing perfusion pressure without reducing total exposure time. This was accomplished by intermittent external compression of the left ventricle during the slow inflow of vectors, thus simulating higher pulsatile pressure. Allografts infected in this manner showed more even distribution of $\beta$-galactosidase expression, as shown in Fig. $2, D$. Average ratio of cells expressing $\beta$-galactosidase was $40 \%$ in subepicardial regions and $25 \%$ in the inner subendocardial regions.

Allograft rejection. Grafts for evaluation of alloreactivity were infected by means of the slow infusion method $(1 \mathrm{ml} / \mathrm{min})$. Allografts infected with the "empty" Ad5dl434 virus $(n=12)$ maintained mechanical activity for $6.9 \pm 0.9$ days. Progressive enlargement, hardening, and shallowness occurred in all control grafts starting on postoperative day 5 . 

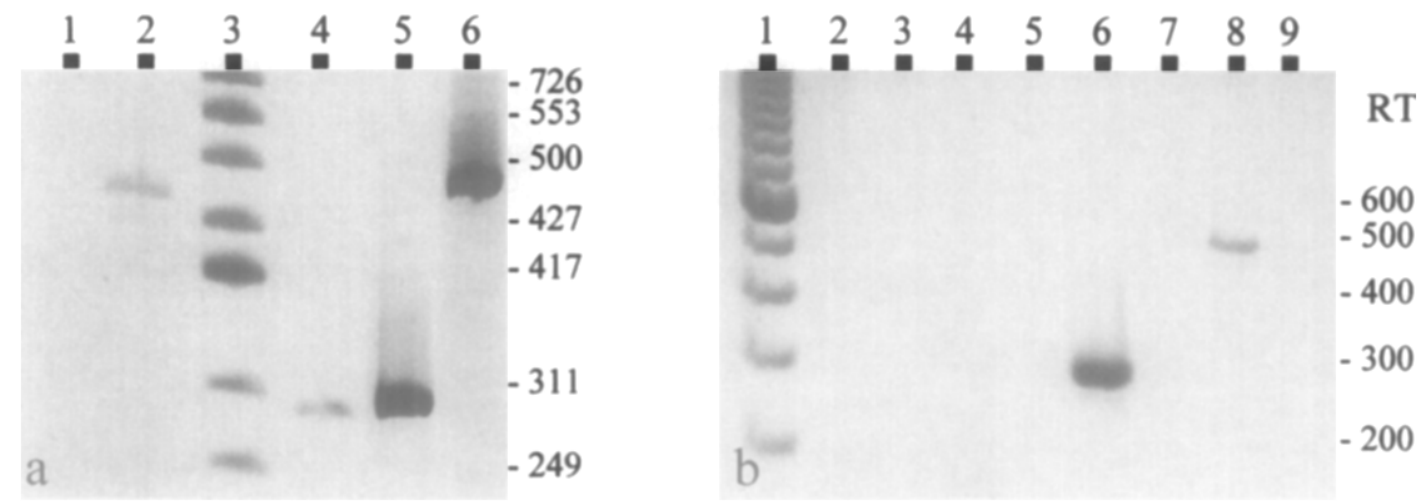

Fig. 1. a, Detection of expected cytokine gene sequences by PCR at $461 \mathrm{bp}$ (vIL-10) and at $243 \mathrm{bp}$ (TGF- $\beta_{1}$ ) in DNA extract from representative corresponding cardiac allografts collected after cessation of mechanical activity. DNA was visualized by ethidium bromide staining. Lane 1, Ad5d1434 (control virus) tested negative. Lane 2, AdSvIL10-infected graft. Lane 3, Ladder marker. Lane 4, AdCMVTGF- $\beta$-infected graft. The corresponding plasmids served as positive controls: Lane 5, The TGF- $\beta_{1}$-encoding plasmid (pHCMVAdhTGF). Lane 6, The vIL-10 encoding plasmid (pAdSvIL10). b, Detection of gene expression in allografts collected 4 days after adenoviral infection. Total RNA was extracted from frozen specimens, reverse-transcribed, amplified by PCR, and probed for the presence of vIL-10 and human TGF- $\beta_{1}$. Lane 1, Ladder marker. Lanes 2 and 3, Ad5dl434-infected graft (negative control). Lanes 4 and 5, AdCMVLacZinfected graft. Lanes 6 and 7, AdCMVTGF- $\beta$-infected graft demonstrates transcription of TGF- $\beta_{1}$ (lane 6) but not vIL-10 (lane 7). Lanes 8 and 9, AdSvIL10-infected graft demonstrates transcription of vIL-10 (lane 8 ) but not TGF- $\beta_{1}$ (lane 9).

Maximal allograft survival in this group was 9 days $(n=1)$, with 10 of the 12 grafts beating for 6 to 7 days.

Mean survival for AdCMVTGF- $\beta$-infected grafts $(n=11)$ was $11.1 \pm 1.7$ days (range 9 to 15.5 days, $p<10^{-4}$ compared with controls). All but one graft in this group survived 10 days or longer, with clinical rejection starting at 8 to 13 days.

AdSvIL10-infected allografts $(n=11)$ survived for an average of $11.2 \pm 3$ days $\left(p<10^{-4}\right.$ compared with controls). Although graft survival was distinctly prolonged by vIL-10 gene transfer, allografts in this group seemed to fall in two separate categories, surviving either 8 to 9.5 days $(n=7)$ or 14 to 16.5 days $(n=4)$. This finding could not be attributed to any specific divergence in treatment, including vector delivery, ischemic time, or other surgical or experimental factors. Clinical allograft deterioration started, correspondingly, either on day 7 or after day 13 postoperatively. Kaplan-Meier cumulative survival curves were derived for the three groups (Fig. 3).

Histologic rejection was assessed blindly by a pathologist unaware of study design. Lowest, highest, and majority scores were assigned. Left and right ventricular and septal specimens were analyzed, and averaged "majority" scores for each graft were used. Scores averaged grade 3 to $3 \mathrm{~B}$ and were similar among the three study groups. Rejection scores were plotted against allograft survival period for the individual grafts, then average slopes were compared among the study groups (Fig. 4). Average rejection slopes for both AdCMVTGF- $\beta$ and AdSvIL10-infected grafts $(0.3 \pm 0.06$ and $0.23 \pm$ 0.05 , respectively) were significantly lower than for controls $(0.46 \pm 0.15, p<0.001$ and $p<0.0005$, respectively).

A predominant part of the immune modulation by both TGF- $\beta_{1}$ and IL-10 is effected by alteration of antigen-presenting cell function. Because antigen recognition and immune activation commence immediately after exposure to alloantigen, we speculated that these occurrences within the 6 to 10 hours before the rise of transgene protein expression may limit the in vivo efficacy of isolated gene therapy. To perturb immunity at this stage, cyclosporine A (INN: ciclosporin) was administered in the perioperative period to recipients of AdCMVTGF- $\beta$ and AdSvIL10-infected grafts: intravenous doses of 5 $\mathrm{mg} / \mathrm{kg}$ were administered 1 hour before the operation and repeated after the completion of the operation. Serum levels of cyclosporine A before the second dose were 150 to $170 \mu \mathrm{g} / \mathrm{L}$, a range that has been shown to prevent rejection of cardiac allografts 

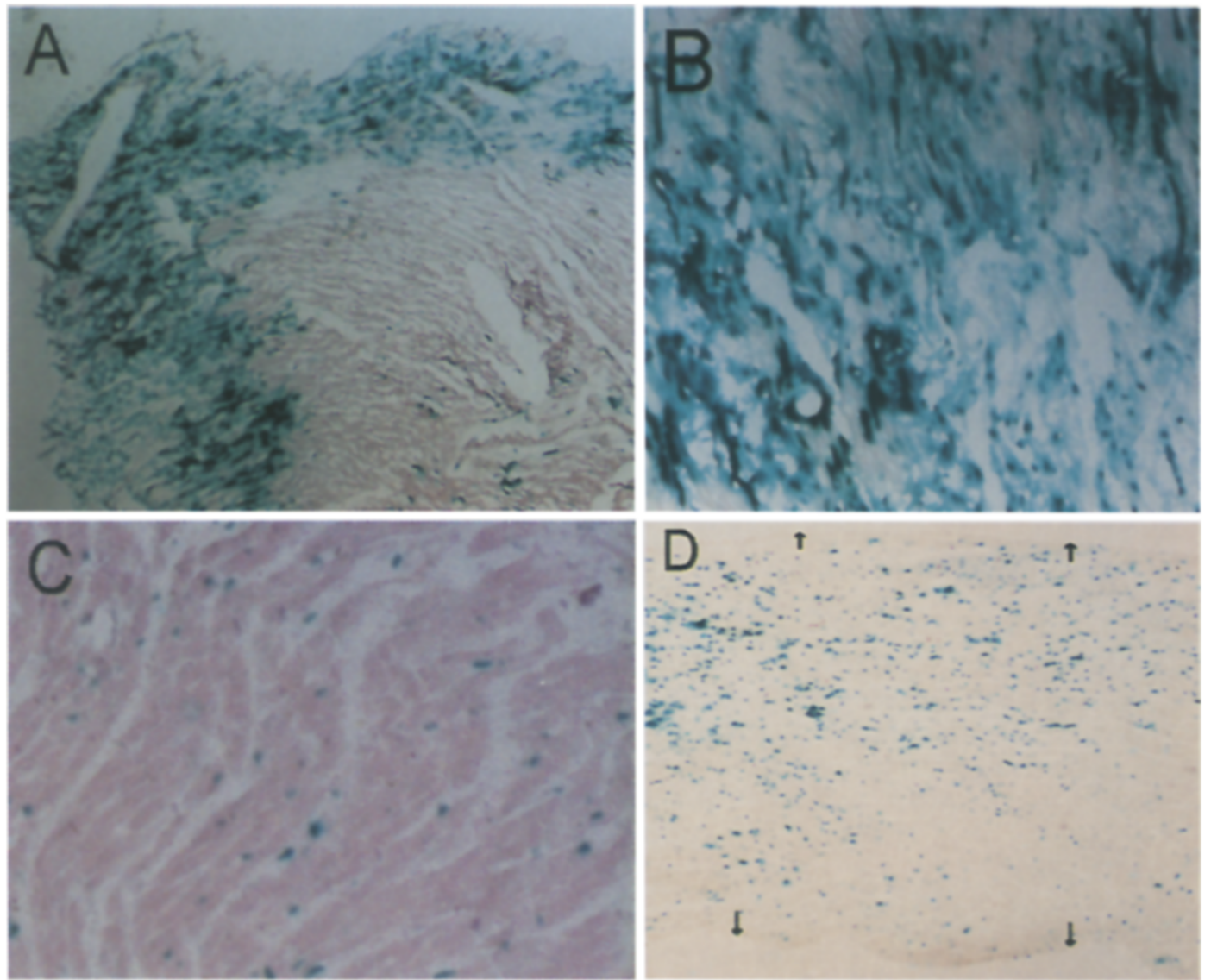

Fig. 2. Patterns of reporter gene expression in cardiac allografts infected with AdCMVLacZ using various intracoronary slow-administration techniques. Grafts were collected 4 days after intracoronary transduction with AdCMVLacZ. A, Continuous low-pressure intracoronary delivery at $1 \mathrm{ml} / \mathrm{min}$ results in uneven myocardial distribution: B, Extremely efficient transfer in subepicardial perivascular areas but (C) much lower expression in inner portions of the left ventricle. $\mathbf{D}$, Intermittent external compression was used to increase delivery pressure without reducing the duration of exposure. This resulted in more homogenous transmural distribution. Solid arrows, Epicardium. Broken arrows, Endocardium.

in New Zealand White rabbits. ${ }^{26}$ As shown in Fig. 5, survival of AdCMVTGF- $\beta$-infected grafts $(n=4)$ was not affected by perioperative administration of cyclosporine A. However, an unexpected reduction in survival of AdSvIL10-infected allografts $(n=4$, $p=0.003$ ) was observed, to the level of control Ad5d1434-infected grafts.

\section{Discussion}

The present study constitutes a first report of a working allograft-targeted gene therapy strategy in the heart transplant setting. It demonstrates the ability of exogenous immunosuppressive cytokine genes delivered by ex vivo intracoronary gene transfer to effect a significant inhibitory action on acute allograft rejection. Adenovirus-mediated delivery of both the vIL-10 and human TGF- $\beta_{1}$ genes during allograft cold preservation resulted in efficient vector uptake, internalization, transcription, and intragraft expression of both cytokines. Prolongation of allograft survival, although temporary, was evident and highly significant, suggesting that this approach may be used to facilitate transplantation.

Recent studies from this and other laboratories have qualitatively demonstrated the feasibility of intracoronary myocardial gene transfer, using cationic liposomes and adenoviral vectors. ${ }^{6,-10,27}$ Replication-defective adenoviral vectors are currently the most efficient vehicle for in vivo gene transfer into nondividing cells such as myocytes, being at least 20 times more potent than the newest liposomal compounds. ${ }^{28}$ Exogenous DNA up to $8.3 \mathrm{~kb}$ can 


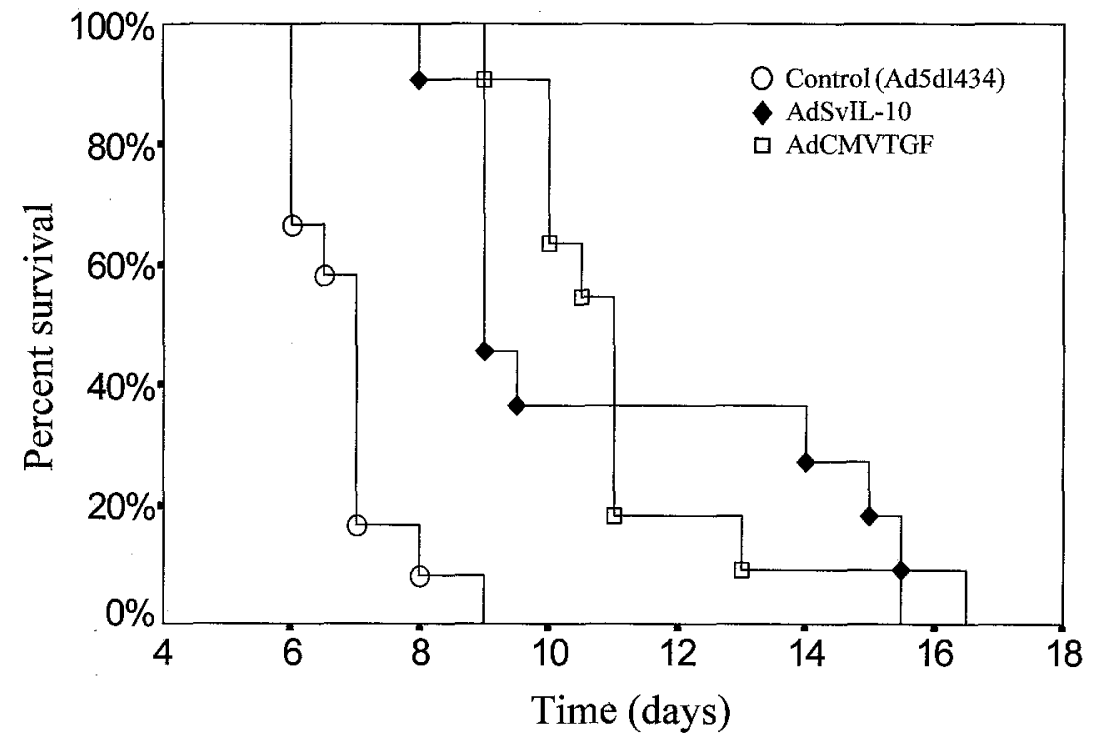

Fig. 3. Kaplan-Meier survival curves for control (Ad5d1434), AdSvIL10, and AdCMVTGF- $\boldsymbol{\beta}_{1}$-infected allografts. Significant prolongation of survival was observed with both cytokines but was more consistent with TGF- $\beta_{1}$.

be used to replace the viral early expression regions E1 and E3 or partly E4. ${ }^{29}$ Although the use of viral vectors in vivo raises safety concerns, the widespread type 5 adenovirus has not been associated with any known malignancies and has been used for routine vaccination in human beings with no apparent side-effects. ${ }^{30}$ The viral particle enters the cell by way of a two-stage process: high-affinity membrane binding occurs by way of the fiber protein, a step that is unaffected by hypothermic conditions. Internalization is then mediated by interaction of the penton base with cellular alpha $\mathrm{v}$ beta 3 and 5 integrins (the vibronectin-binding proteins). ${ }^{31}$ This process is energy-dependent and occurs under normothermic conditions after graft reperfusion. After endocytosis and cytoplasmic release of the fiber, penton base, and capsid-stabilizing proteins, up to $80 \%$ of internalized viral particles reach the nucleus, where the viral genome remains episomal, thus resulting in transient expression. ${ }^{32}$ This short-lived duration of transgene expression currently limits the potential usefulness of first-generation adenoviral vectors for in vivo gene therapy.

The current study first evaluated the magnitude and transmural distribution of gene expression in allografts infected during cold preservation with adenoviral vectors encoding a reporter gene $(\beta$ galactosidase). The use of reporter genes allows direct visualization of the transduced cells by enzy- matic staining, thus having the advantage of easy localization of gene expression. The efficacy of gene transfer obtained in the present study by slow lowpressure intracoronary infusion of vectors under hypothermic conditions is comparable with that previously reported with normothermic transcatheter intracoronary infusion in vivo ${ }^{7}$ and represents the highest myocardial transduction ratios to date. However, transmural expression of vectors administered in this fashion was not homogeneous: whereas subepicardial perivascular regions were transduced with very high efficacy, $\beta$-galactosidase expression in subendocardial areas was considerably lower. This finding may be due to high-affinity adherence of the vectors to proximal first-encountered cells, made possible by the slow delivery rate. When soluble cytokine genes are being transferred, this may not necessarily lessen an in vivo effect, because secreted proteins may act within the graft without requiring uniform myocardial expression. Nevertheless, some gene transfer applications (e.g., neoangiogenesis or enhancement of contractile function) may require homogeneous transgene distribution. We demonstrated that a more uniform distribution of transgene expression throughout the myocardium can be achieved by pulsatile administration of the vectors at higher perfusion pressure without reducing the duration of inflow, a method easily applicable clinically. 


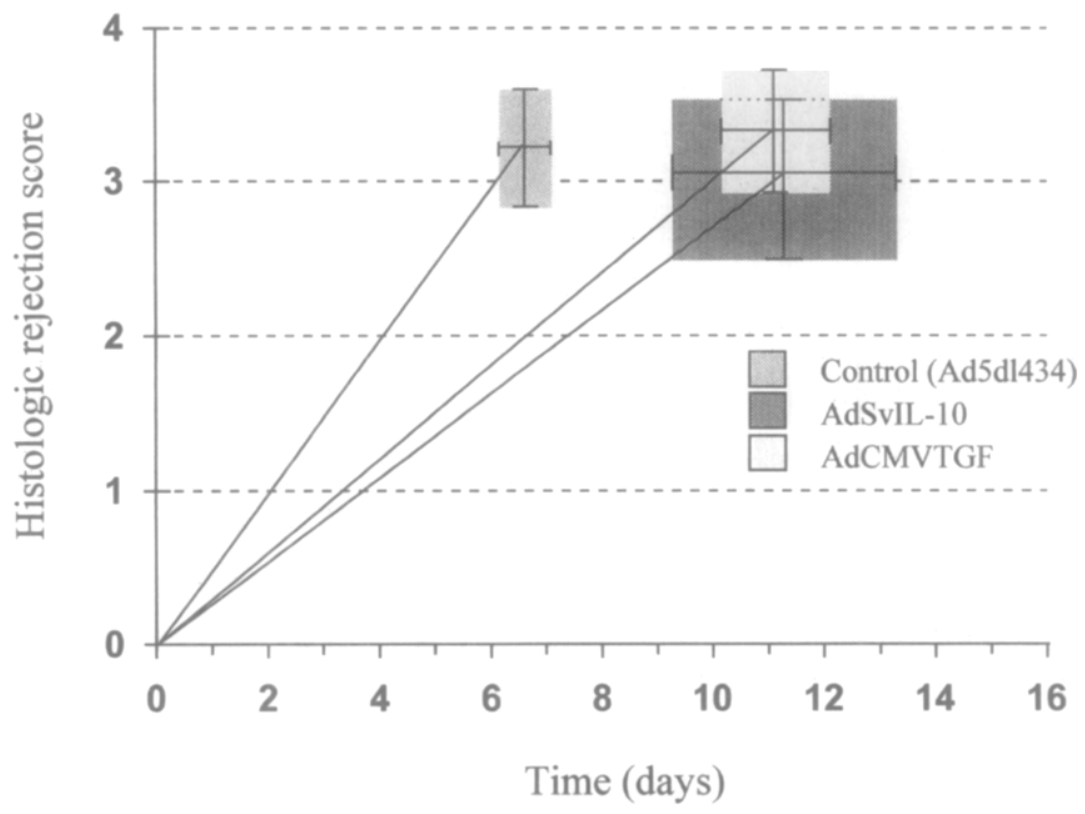

Fig. 4. Histologic rejection scores for allografts infected with Ad5dl434, AdCMVTGF- $\beta_{1}$ and AdSvIL10, using the International Society for Heart Transplantation classification. Rejection scores and allograft survival are expressed as mean \pm standard deviation. Scores were similar between the study groups, but rejection slopes were significantly lowered by immunosuppressive cytokine gene transfer.

In the present study, an initial $60 \%$ prolongation of allograft survival was followed by graft rejection, suggesting that cytokine levels were temporarily sufficient to achieve an in vivo effect. The time course of graft failure corresponds to the time frame of adenoviral vector transgene expression as documented by reports of in vivo gene transfer. ${ }^{6,7,33}$ It is therefore plausible that the decline in cytokine expression be a reason for graft failure. The mechanism causing the transience of expression of genes transferred by adenoviral vectors is not fully understood. Cellular and humoral host immune responses have been shown to be activated against both the adenovirus group antigen and the encoded transgene within 2 weeks of intramuscular vector administration in mice, and systemic immunosuppression has significantly prolonged gene expression. ${ }^{34}$ However, liposomal gene delivery results in only marginal prolongation of expression. More recently, it has been suggested that humoral immune response to non-self transgene-encoded proteins, rather than viral proteins, is responsible for this observed instability of transgene expression, as well as the relative inefficacy of repeated vector administration. ${ }^{35}$ Whereas TGF- $\beta_{1}$ has down-regulating effects on B-cell proliferation and antibody production, vIL-10 actually promotes differentiation and proliferation of $\mathrm{B}$ cells along their maturation stages. ${ }^{12}$ This opposed action on humotal responses might explain the more consistent prolongation of allograft survival observed with TGF- $\beta_{1}$. The finding that transfer of a self-protein gene results in stable long-term expression under identical conditions in immunocompetent animals ${ }^{35}$ is encouraging, because most candidates for clinical gene therapy applications are ubiquitous proteins such as cytokines, enzymes, receptors, and growth factors. ${ }^{36}$ Future research should evaluate the usefulness of gene therapy strategies inducing overexpression of such self-proteins.

A vector absorption ratio above $80 \%$ was maintained in the present study with all four vectors. We previously found the absorbed fraction of adenoviral vectors administered by ex vivo slow intracoronary infusion to be remarkably constant over a wide range of doses, despite hypothermic $\left(4^{\circ} \mathrm{C}\right)$ conditions. Moreover, expression of TGF- $\beta_{1}$ correlated with the infused (and absorbed) quantity of AdCMVTGF- $\beta$ in a dose-dependent manner. ${ }^{18}$ These results are encouraging, because high doses of vectors may be administered without saturating allograft receptors and may increase the initial amount of expressed protein. The detection of both expressed cytokines in corresponding recipient se- 


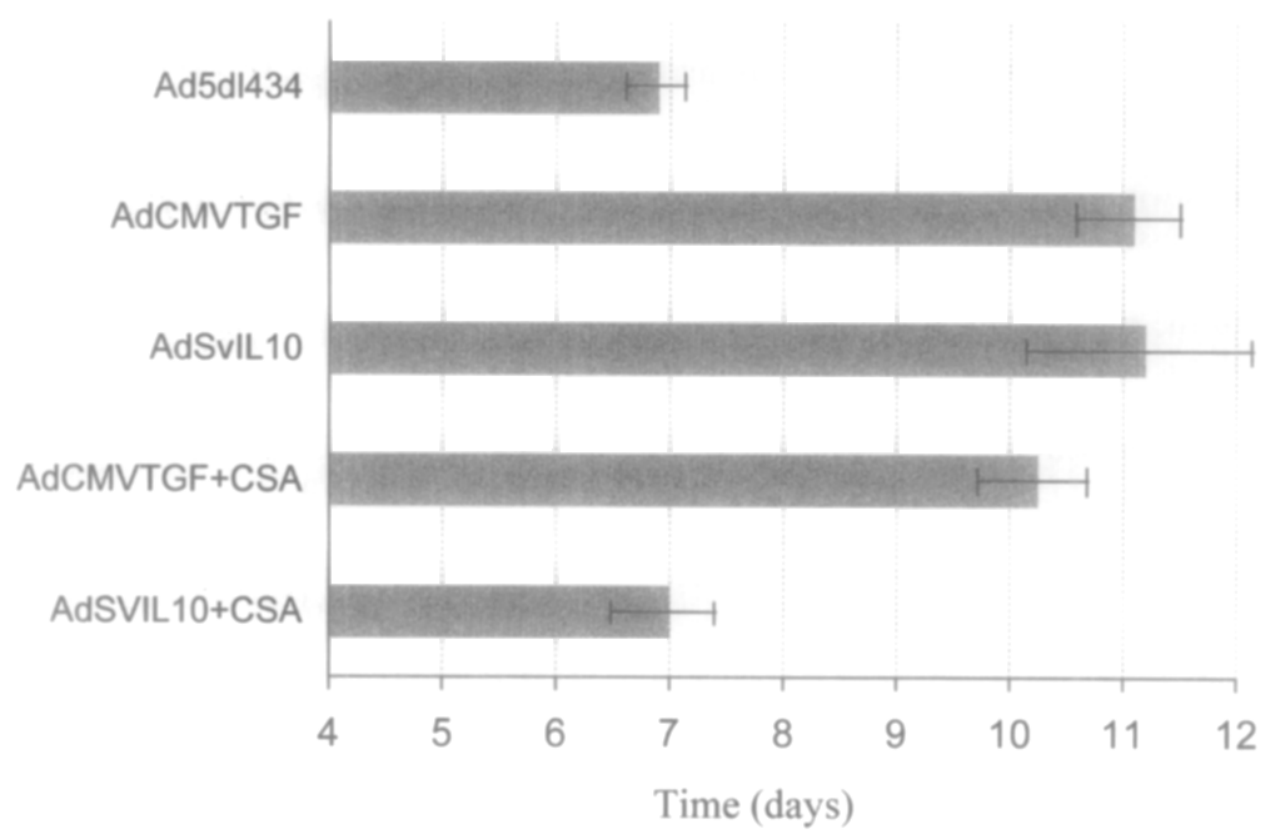

Fig. 5. Average duration of allograft survival: Perioperative administration of cyclosporine A (CSA) did not notably alter survival of AdCMVTGF-infected allografts, but survival of AdSvIL10-infected grafts was reduced compared with that observed in control grafts.

rum (see Table I) suggests that a significant amount of protein is secreted by the allografts. Although it cannot be ruled out that part of this protein is secreted by remote recipient cells infected with virus shed from the coronary bed during graft reperfusion, we believe this amount to be small, based on the small volume of the rabbit coronary tree and the high dilution of administered virus. However, we cannot rule out the possibility of a systemic immunosuppressive effect mediated by the secreted cytokine fraction. In a recent report, prolongation of the survival of nonperfused neonatal mouse donor hearts transduced by retrovirus-mediated transfer of the vIL-10 gene was found to be due to local rather than systemic immunosuppression. ${ }^{37}$ However, vIL-10 was not detectable in the serum of recipient mice in that report.

Perioperative administration of high-dose cyclosporine A failed to further prolong allograft survival. The rationale for cyclosporine $A$ administration at this time was to provide transient inhibition of cellular immune activation and antigen-presenting cell function for the duration of initial transcription and translation of the inserted genes. These processes occur immediately after graft reperfusion and, therefore, are not within the time frame of transgene expression. Although cyclosporine A had no effect on survival of AdCMVTGF- $\beta$-infected grafts, the survival of AdSvIL10-infected grafts was significantly shortened by perioperative administration of cyclosporine A. Inadequate time frame or magnitude of cyclosporine A-induced immunosuppression may partly explain these results; however, an important difference between the two cytokines lies in their different interspecies homology. Whereas TGF- $\beta_{1}$ is highly similar between species, IL-10 varies structurally and functionally: ${ }^{13}$ In our rabbit model, vIL-10 allogenicity may have precipitated an accelerated immune response to this nonself encoded protein in the setting of delayed antigen presentation effected by cyclosporine A. A recent finding by van Bergen and associates ${ }^{38}$. may provide a clue to the mechanism of IL-10-mediated acceleration of graft rejection in the presence of antigen-presenting cell suppression. Although IL-10 is known to inhibit antigen-induced T-cell proliferation in the presence of antigen-presenting cells, the authors found that in the absence of antigen-presenting cells, this cytokine strongly stimulated proliferation of CD8+ cytotoxic T-lymphocyte clones. These in vitro results suggest a dichotomy of IL-10 immunomodulatory function early and late in the allogeneic immune response. To determine the mechanisms by which the two cytokines exert their 
immunosuppressive effect in vivo, further research will include an analysis of the graft cellular infiltrate and quantitation of alloantigen-specific cytotoxic and helper T-cell precursors, in addition to cytokine expression profiles within the grafts.

The ability to transfer working recombinant genes to cardiac allografts at the time of preservation, as demonstrated in the present study, has potentially far-reaching clinical and research applications. In the long term, this approach may be part of a strategy to provide a milieu in which organ-specific tolerance may be achieved by the use of adjuvant time-limited measures. In addition, therapies involving gene transfer can be envisioned that would improve early posttransplantation myocardial contractility and endothelial function or prevent late allograft vasculopathy. However, the limitations of currently available vectors must first be overcome to improve the stability of transgene expression. Promising strategies aimed at extending the expression of transferred genes include further deletions in second- and third-generation adenoviruses, ${ }^{39,40}$ systemic immunosuppression, ${ }^{34}$ use of self-protein encoding genes, ${ }^{35}$ use of genome-integrating vectors, ${ }^{37,41}$ and construction of new recombinant vectors. Especially promising is the recent demonstration of long-term myocardial transgene expression induced by transcatheter intracoronary delivery of adeno-associated viral vectors. ${ }^{42}$ The use of this genome-integrating vector has been impeded until recently by the difficulty of obtaining high viral titers free of helper adenovirus contamination, but this may no longer be an obstacle. ${ }^{43}$ If successful, allograft-targeted gene therapy alone or a combination of gene transfer with time-limited pharmacologic interventions may prove to be an important alternative to conventional systemic immunosuppression.

\section{REFERENCES}

1. Acsadi G, Jiao SS, Jani A, et al. Direct gene transfer and expression into rat heart in vivo. New Biologist 1991;3:71-81.

2. Brody SL, Crystal RG. Adenovirus-mediated in vivo gene transfer. Ann N Y Acad Sci 1994;716:90-101; discussion 101-3.

3. Buttrick PM, Kass A, Kitsis RN, et al. Behavior of genes directly injected into the rat heart in vivo. Circ Res 1992;70:193-8.

4. Lin H, Parmacek MS, Morle G, et al. Expression of recombinant genes in myocardium in vivo after direct injection of DNA. Circulation 1990;82:2217-21.

5. Guzman RJ, Lemarchand P, Crystal RG, et al. Efficient gene transfer into myocardium by direct injection of adenovirus vectors. Circ Res 1993;73:1202-7.

6. Lee J, Laks H, Drinkwater DC, et al. Cardiac gene transfer by intracoronary infusion of adenovirus vector-mediated reporter gene in the transplanted mouse heart. J Thorac Cardiovase Surg 1996;111:246-52.

7. Barr E, Carroll J, Kalynych AM, et al. Efficient cathetermediated gene transfer into the heart using replicationdefective adenovirus. Gene Ther 1994;1:51-8.

8. Ardehali A, Fyfe A, Laks H, et al. Direct gene transfer into donor hearts at the time of harvest. J Thorac Cardiovasc Surg 1995;109:716-20.

9. Giordano FJ, Ping P, McKirnan MD, et al. Intracoronary gene transfer of fibroblast growth factor-5 increases blood flow and contractile function in an ischemic region of the heart. Nature Med 1996;2:534-9.

10. Sawa Y, Suzuki K, Bai HZ, et al. Efficiency of in vivo gene transfection into transplanted rat heart by coronary infusion of HVJ liposome. Circulation 1995;92:11479-82.

11. de Waal Malefyt $\mathrm{R}$, Haanen J, Spits $\mathrm{H}$, et al. Interleukin 10 (IL-10) and viral IL-10 strongly reduce antigen-specific human $T$ cell proliferation by diminishing the antigen-presenting capacity of monocytes via downregulation of class II major histocompatibility complex expression. J Exp Med 1991;174:915-24.

12. Moore KW, A OG, de Waal Malefyt R, et al. Interleukin-10. Annu Rev İmmunol 1993;11:165-90.

13. De Vries JE dWMR. Interleukin-10: Austin: RG Landes; Boca Raton (FL): CRC Press; 1995.

14. Hsu DH, de Waal Malefyt R, Fiorentino DF, et al. Expression of interleukin-10 activity by Epstein-Barr virus protein BCRF1. Science 1990;Nov:831.

15. Espevik T, Figari IS, Shalaby MR, et al. Inhibition of cytokine production by cyclosporin $\mathrm{A}$ and transforming growth factor beta. J Exp Med 1987; 166:571-6.

16. Espevik T, Waage A, Faxvaag A, Shalaby MR. Regulation of interleukin-2 and interleukin-6 production from T-cells: involvement of interleukin-1 beta and transforming growth factor-beta. Cell Immunol 1990;126:47-56.

17. Smyth MJ, Strobl SL, Young HA, et al. Regulation of lymphokine-activated killer activity and pore-forming protein gene expression in human peripheral blood CD8 $+\mathrm{T}$ lymphocytes: inhibition by transforming growth factor-beta. J Immunol 1991;146:3289-97.

18. Brauner $\mathrm{R}, \mathrm{Wu} \mathrm{L}$, Laks $\mathrm{H}$, et al. Intracoronary gene transfer of immunosuppressive cytokines to cardiac allografts: method and efficacy of adenovirus-mediated transduction. J Thorac Cardiovasc Surg 1997:113:1059-67.

19. Barker DD, Berk AJ. Adenovirus proteins from both E1B reading frames are required for transformation of rodent cells by viral infection and DNA transfection [published erratum appears in Virology 1987 May;158:263]. Virology 1987;156:107-21.

20. Jones $\mathrm{N}$, Shenk $\mathrm{T}$. Isolation of adenovirus type 5 host range deletion mutants defective for transformation of rat embryo cells. Cell 1979;17:683-9.

21. Morsy MA, Alford EL, Bett A, et al. Efficient adenoviralmediated ornithine transcarbamylase expression in deficient mouse and human hepatocytes. J Clin Invest 1993; 92:1580-6.

22. Grodzicker T, Klessig DF. Expression of unselected adenovirus genes in human cells co-transformed with the HSV-1 tk gene and adenovirus 2 DNA. Cell 1980;21:453-63.

23. McGrory WJ, Bautista DS, Graham FL. A simple technique 
for the rescue of early region mutations into infectious human adenovirus type 5. Virology 1988;163:614-7.

24. Brillantes AM, Allen P, Takahashi T, et al. Differences in cardiac calcium release channel (ryanodine receptor) expression in myocardium from patients with end-stage heart failure caused by ischemic versus dilated cardiomyopathy [published erratum appears in Circ Res 1992 Dec;71:1538]. Circ Res 1992;71:18-26.

25. Billingham ME, Cary NK Hammond ME, et al. A working formulation for the standardization of nomenclature in the diagnosis of heart and lung rejection: Heart Rejection Study Group. The International Society for Heart Transplantation. J Heart Transplant 1990;9:587-93.

26. Fryer J, Yatscoff RW, Pascoe EA, Thliveris J. The relationship of blood concentrations of rapamycin and cyclosporine to suppression of allograft rejection in a rabbit heterotopic heart transplant model. Transplantation 1993; 55:340-5.

27. Dalesandro J, Akimoto H, Gorman CM, et al. Gene therapy for donor hearts: ex vivo liposome-mediated transfection. J Thorac Cardiovase Surg 1996;111:416-22.

28. Stephan DJ, Yang ZY, San $\mathrm{H}$, et al. A new cationic liposome DNA complex enhances the efficiency of arterial gene transfer in vivo. Hum Gene Ther 1996;7:1803-12.

29. Bett AJ, Haddara W, Prevec L, Graham FL. An efficient and flexible system for construction of adenovirus vectors with insertions or deletions in early regions 1 and 3. Proc Nat1 Acad Sci U S A 1994;91:8802-6.

30. Rubin B, Rorke L. In: Adenovirus vaccines. Philadelphia: WB Saunders; 1988.

31. Goldman MJ, Wilson JM. Expression of alpha $v$ beta 5 integrin is necessary for efficient adenovirus-mediated gene transfer in the human airway. J Virol 1995;69:5951-8.

32. Greber U, Willets $M$, Webster P, Helenius A. Stepwise dismantling of adenovirus 2 during entry into cells. Cell 1993; 75:477-86.

33. Drazan KE, Wu L, Olthoff KM, et al. Transduction of hepatic allografts achieves local levels of viral IL-10 which suppress alloreactivity in vitro. J Surg Res 1995;59:219-23.
34. Vilquin JT, Guerette B, Kinoshita I, et al. FK506 immunosuppression to control the immune reactions triggered by first-generation adenovirus-mediated gene transfer. Hum Gene Ther 1995;6:1391-401.

35. Tripathy SK, Black HB, Goldwasser E, Leiden JM. Immune responses to transgene-encoded proteins limit the stability of gene expression after injection of replication-defective adenovirus vectors. Nature Med 1996;2:545-50.

36. Schneider MD, French BA. The advent of adenovirus: gene therapy for cardiovascular disease. Circulation 1993;88(4 Pt 1):1937-42.

37. Qin L, Chavin KD, Ding $\mathrm{Y}$, et al. Retrovirus-mediated transfer of viral $\mathrm{IL}-10$ gene prolongs murine cardiac allograft survival. J Immunol 1996;156:2316-23.

38. van Bergen CA, Smit WM, van Sluijters DA, et al. Interleukin-10, interleukin-12, and tumor necrosis factoralpha differentially influence the proliferation of human CDS + and CD4+ T-cell clones. Ann Hematol 1996;72: 245-52.

39. Engelhardt JF, Ye X, Doranz B, Wilson JM. Ablation of E2A in recombinant adenoviruses improves transgene persistence and decreases inflammatory response in mouse liver. Proc Natl Acad Sci U S A 1994;91:6196-200.

40. Fisher KJ, Choi H, Burda J, et al. Recombinant adenovirus deleted of all viral genes for gene therapy of cystic fibrosis. Virology 1996;217:11-22.

41. Berns KI, Giraud C. Adenovirus and adeno-associated virus as vectors for gene therapy. Ann N Y Acad Sci 1995;772:95104.

42. Kaplitt MG, Xiao X, Samulski RJ, et al. Long-term gene transfer in porcine myocardium after coronary infusion of an adeno-associated virus vector. Ann Thorac Surg 1996;62: 1669-76.

43. Tamayose K, Hirai Y, Shimada T. A new strategy for large-scale preparation of high-titer recombinant adenoassociated virus vectors by using packaging cell lines and sulfonated cellulose column chromatography. Hum Gene Ther 1996; 7:507-13. 